\title{
Experimental and modelling investigation of mechanical behaviour of ageing concrete
}

\author{
H Mamand, J Chen* and S J Barnett \\ School of Civil Engineering and Surveying, Faculty of Technology \\ University of Portsmouth, Portland Street, Portsmouth PO1 3AH, UK
}

\begin{abstract}
To be able to investigate an ageing concrete behaviour a material model is developed by this investigation in terms of tested material samples taken from the ageing concrete structure. The splitting tensile test is modified with a lateral expansion measurement rig to observe the load-displacement response in the splitting test. A set of material properties is determined based on experimental work and successfully used to create a material damage model for investigating the mechanical behaviour of the ageing concrete. A FEA model with this developed ageing concrete material model (ACMM) is used in simulation of selected concrete core sample tests including the splitting test. Comparison between tests and modelling simulations shows that the developed ageing concrete material model is working well. The outcomes from this investigation supplies an approach to widely investigate engineering materials with ageing problems.
\end{abstract}

Keywords: Ageing concrete, ageing concrete material model, adjusted splitting test, FEM analysis.

\section{Introduction}

The marine environment has severe effects on reinforced concrete structures. Concrete structures are subjected to different processes and mechanisms of deterioration and degradation based on the exposure conditions, ranging from aesthetic damage to severe structural deterioration. Around the globe, numerous marine structures and bridges are largely affected by structural capacity degradation due to ageing and environmental impacts [1]. In the UK, most of the existing reinforced concrete structures in the marine environment show signs of distress and have deteriorated over time.

*Corresponding address: jiye.chen@ port.ac.uk 
Port operations are an important tool that support UK's maritime trade and maintain its position as a world-leading maritime centre. The Hampshire coast covers one of the heavily urbanised and densely populated ports of Britain, containing major military, commercial and historical assets. Due to importance of these structures it is essential to regularly assess and monitor the port's physical infrastructure to ensure smooth port activities.

The ageing concrete infrastructures in Hampshire coast (like other coast infrastructures in England) have experienced deterioration due to structural exposure conditions and ageing. For instance, the Floating Dock Jetty in the Portsmouth International Port on the Hampshire coast has suffered deterioration and ageing-related degradation. The jetty was built in 1906 and has now reached the end of its design life; the 110-year-old jetty is restrained in use due to ageing effects and must be demolished. The ageing concrete beam investigated in this research is from the valuable historic jetty in Hampshire coast. This is an over 70 years reinforced concrete jetty affected by ageing and aggressive environmental conditions which showed all signs of distress. From the site inspection, the most severe structural beam element is selected for this investigation.

Previous researchers have used different methods to investigate ageing concretes and assess the stiffness and strength degradation. Lakshmikandhan et al. [1] investigated the damages in reinforced concrete by observing the stiffness degradation in the damaged beam. They used static test approach to define the reduction in the load deflection response of the beam. Bourahla et al. [2] used stiffness degradation to investigate the influence of the reduction in structural capacities occurred due to ageing and material deterioration over time. They developed a mathematical model to simulate the damage in a concrete structure using both stiffness and strength with a degradation factor in the model, and found that the stiffness and strength degradation correlate to the ageing effect. Timothy and Dolen [3] also studied degradation due to ageing effects in the concrete structures. By a developed model to predict the changes in strength and stiffness, they found that the deteriorated structure no longer withstands the design load due to the ageing effect. Other researchers such as Zhu and Law [4], Sanayei and Onipede [5] and Cerri and Vestroni [6] also used similar approaches to define the level of the damage in structures. Their assessment approaches were based on the reduction of the load bearing capacity of the structural elements. 
This paper presents both experimental and finite element modelling investigation on mechanical behaviour of ageing concrete. The samples of ageing concrete were taken from a marine infrastructure and tested to examine its basic mechanical behaviour. Corresponding tested data are used to create a numerical ageing concrete material model (ACMM) for analysing the ageing concrete performance. This model is implemented into a user subroutine UMAT in commercial FEA software ABAQUS to simulate the sample test. Because the determination of concrete properties is essential in the assessment of concrete structures, hence, to have a reliable estimation of in-situ material properties, the mechanical properties of the ageing concrete are obtained from experimental tests using core samples taken from the ageing infrastructure. Allen [7] stated that the only reliable method for measuring concrete properties is through drilling core samples from the structure. Testing the core samples are conducted according the standardized procedures of BS EN Standards to determine ageing concrete properties, which included tensile and compressive strength, Young's modulus, Passion ratio and fracture energy. The standard splitting test method is modified with a supplemental rig to monitor the lateral movement and determine the tensile strain which was not investigated by previous researchers. The data from splitting test are used to determine the fracture energy of ageing concrete. Fracture energy is essential to investigate damage behaviour of materials and fracture process. As Ghaemmaghami and Ghaemian [8] stated that fracture energy is an important nonlinear parameter of concrete in studying and predicting fracture behaviour of concrete.

A bilinear cohesive damage model is assumed to define a stress-strain relationship of the ageing concrete in conjunction with experimental data. The cohesive damage model assumes a linear stress softening until collapse point where stress becomes zero. This simple approach corresponded reasonably well with the behaviour of concrete under tension testing [9]. Petersson [10] stated that it is accepted to use a linear descending to define the stress softening behaviour in concrete. The advantage of the bilinear cohesive damage model is that it can be simply adjusted in accordance with concrete properties obtained from the test of ageing concrete. Some material damage models are available in ABAQUS such as concrete damaged plasticity and concrete smeared cracking model. These models would have problems for mesh sensitivity and convergence if refinement mesh is applied in the FEA analysis of plain concrete [11]. 
The summary of the research contribution includes developing an FEA model to perform a numerical investigation of the damaged beam. Correspondingly, a mechanical constitutive model of the aged concrete material is established in conjunction with the experimental tests on aged concrete samples obtained from the ageing structure. The basic mechanical property of the ageing concrete materials is obtained through material sample tests. This founding can be used to further investigate the ageing concrete behaviour.

\section{Experimental Work}

Compressive strength of plain concrete is an important property that can be used to assess the quality of concrete. Seven core samples subjected to a uniaxial compression specified in BS EN 12390-3 [12] are tested to determine the compressive strength of the ageing concrete. The core sample has various diameter D ranged from 93 to $100 \mathrm{~mm}$, its length $\mathrm{L}$ ranged from 93 to $106 \mathrm{~mm}$ [13]. Figure 1 shows a satisfactory compression failure of a core sample. The average compressive strengths fc of seven core samples is $67 \mathrm{MPa}$.

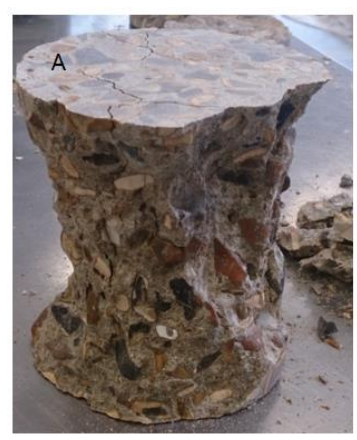

Figure 1, Satisfactory compression failure.

Three core samples are tested by compression to determine the elastic modulus of the ageing concrete. The samples are subjected to a uniaxial cyclic compression load with a maximum load applied equal to one-third of the compression failure strength determined experimentally. The core samples, sized 100 $\mathrm{mm}$ in diameters and $200 \mathrm{~mm}$ in heights, are complied with the requirements of BS EN 12390-1 [14] at the ratio range of 2 to 4 between height and diameter. Preload of $4 \mathrm{kN}$ or $0.5 \mathrm{MPa}$ is applied to the core samples as an initial load. Loading steadily increases at a rate of $0.5 \mathrm{MPa} / \mathrm{s}$ until a peak load 175.32 
$\mathrm{kN}$ or $22.33 \mathrm{MPa}$ is reached as specified in BS EN 12390-13 [15]. The average elastic modulus 38728 MPa is worked out from three samples.

Tensile strength is an important property of concrete to determine the load capacity of concrete structures at which cracks would possibly form and propagate [16]. The standard splitting test method specified in BS EN 12390-6 [17] only measures the failure load or failure strength, it does not include monitoring lateral movement which is important to investigate fracture processes of concrete. As Akita et al. stated [18] that defining tension softening behaviour is essential to analyse the fracture process of concrete. Therefore, the splitting test method is adjusted with a supplemental feature added to the original tensile testing apparatus to control lateral displacement and define tension softening response of the core samples.

A rig designed for lateral expansion measurement of splitting samples is made of S275 steel. The designed rig shown in Figures 2 and 3 includes: two curved steel plates for holding the samples, a 14 mm steel plate for holding the linear variable displacement transducer (LVDT) and two stainless steel 316 bars with $10 \mathrm{~mm}$ diameters. Two stainless steel compression springs are also required to hold the specimens securely without affecting the load-displacement response $[19,20]$. As shown in Figure 4, the test rig is mounted on the sample and the assembly is placed inside a Zwick/Roell Z250 universal testing machine to perform the splitting strength test. The spring-loaded devices are used to clamp the sample across its width with a small lateral compressive force of around $0.005 \mathrm{MPa}$ applied. This lateral force used to hold and secure the curved steel plates is very low, which can be neglected in calculation of tensile strength. Three LVDTs are attached to one of the curved plates along the centre line of the specimen at the different positions along the cylinder length. The LVDTs aims to record the lateral expansions of the sample. A preload of $50 \mathrm{~N}$ is applied prior to starting the test. The test starts with applying a compression line load along the length of the sample with a displacement rate equal to 0.1 $\mathrm{mm} / \mathrm{min}$, i.e. around $0.25 \mathrm{MPa} / \mathrm{min}$. 


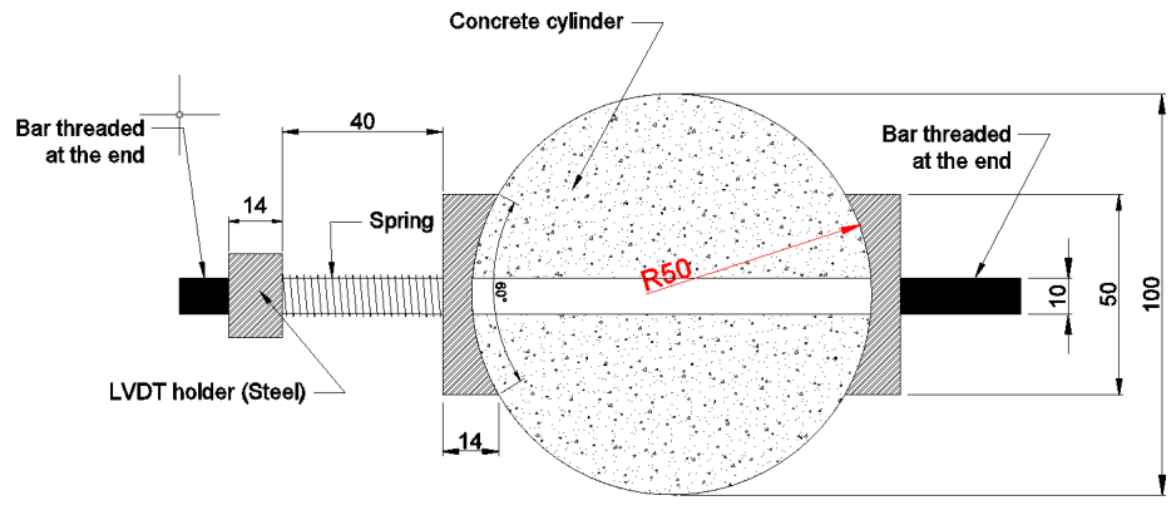

Figure 2, Front elevation of the lateral expansion-measuring rig.

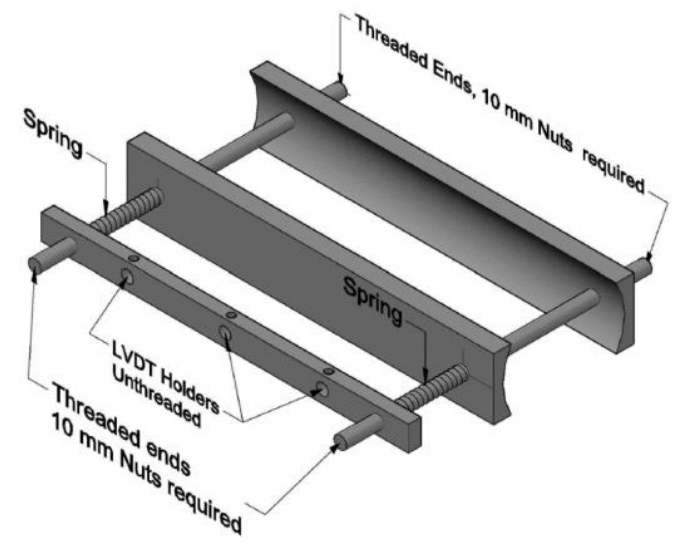

Figure 3, Isometric view of the rig.
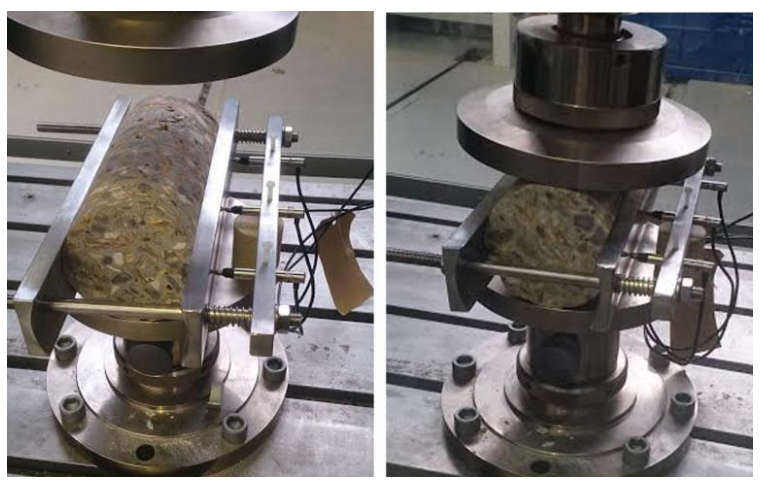

Figure 4, Core samples subjected to splitting test.

Three core samples subjected to the adjusted splitting are tested. Two core samples have satisfactory split failures as shown in Figure 5, the third core sample has unexpected failure due to bulging at midheight of the sample. Bulging in the sample causes shear plane failure due to stress concentration at bulging plane during the loading process. The tested tensile failure loads together with dimension data 
of the core samples are given in Table 1. It can be seen from Table 1 that the average splitting tensile strength of the core samples can be 4.2 MPa. The splitting tensile strength $f_{t}$ at the centre of the core is determined using Equation 1 in accordance to BS EN 12390-6 [17].

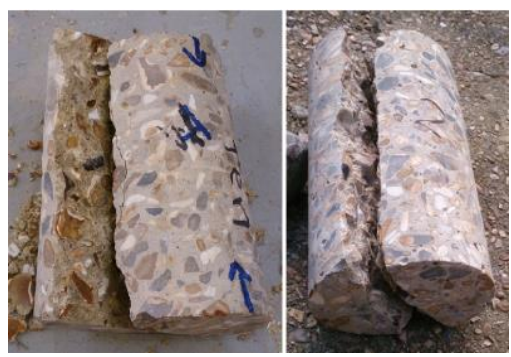

Figure 5, Core samples with satisfactory failure.

Table 1: Tensile failure results of the core sample.

\begin{tabular}{|c|c|c|c|}
\hline Test No. & $\begin{array}{c}\text { Size } \\
\text { DxL }(\mathbf{m m x m m})\end{array}$ & Applied load p (N) & $\begin{array}{c}\text { Tensile Failure } \\
\text { Strength } \boldsymbol{f}_{\boldsymbol{t}} \text { (MPa) }\end{array}$ \\
\hline 1 & $100 \times 200$ & 133029 & 4.20 \\
\hline 2 & $100 \times 200$ & 131825 & 4.19 \\
\hline
\end{tabular}

$f_{t}=\frac{2 p}{\pi L D} M P a$

Where, $\mathrm{p}$ is the applied load, $\mathrm{L}$ and $\mathrm{D}$ are the length and the diameter of the sample, respectively. The experimental data of applied load and lateral displacement recorded by the LDVTs are used to plot tensile stress-strain responses of two core samples as shown in Figure 6. From Figure 6 the adjusted splitting test method conducts an elastic modulus which is close to the average value of compressive elastic modulus $38728 \mathrm{MPa}$. The values of elastic modulus from tension and compression tests would not be exactly same due to differences in boundary conditions and existence of micro crack patterns [21].

The fracture energy of the ageing concrete is important in creating the ACMM, which can be defined as the amount of energy required to generate a tensile crack and failure of a unit area measured by $\mathrm{N} / \mathrm{mm}$ [22]. In this study, fracture energy is determined experimentally from stress-displacement response of the splitting core tests. As showed in Figure 6 the post crack softening parts of the stressdisplacement responses recorded during the splitting tests does not reach the complete failure. Therefore, to determine fracture energy of the core samples the post crack stress softening curves are 
extrapolated to meet the $\mathrm{X}$ axis where stress is zero as shown in Figure 7. The linear descending is an approximation that can be accepted for modelling of concrete [10]. The linear approximation is used as a linear softening model, in conjunction with the experimental data, to address a damage evolution in the post failure response.
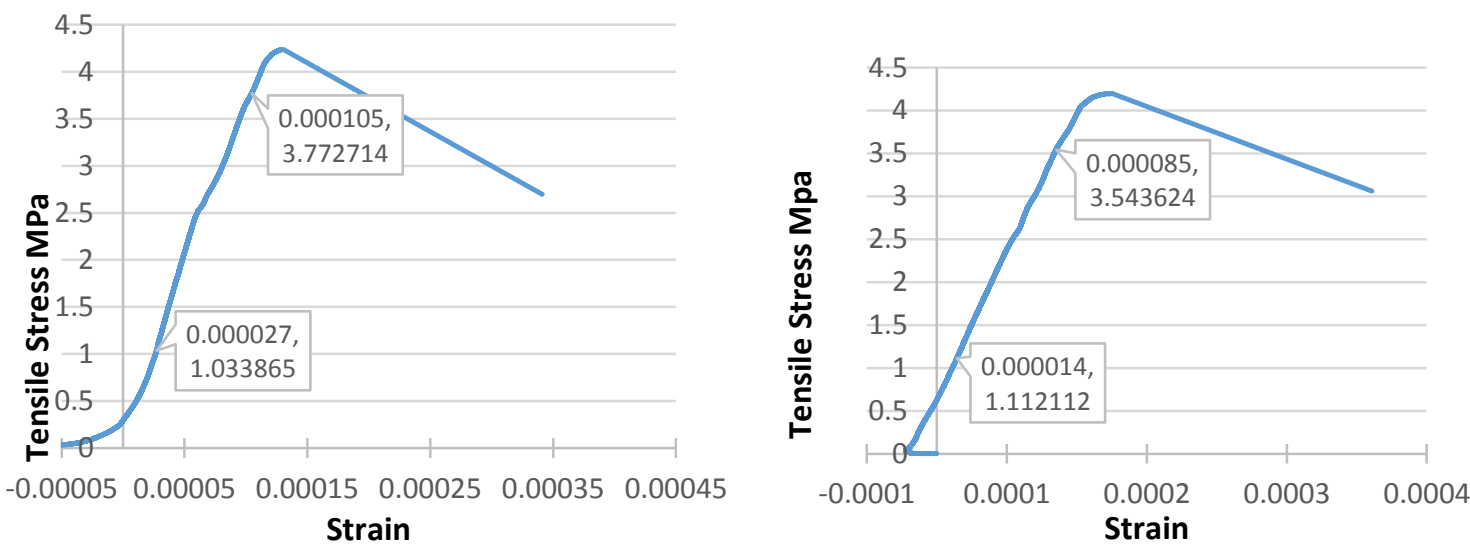

Figure 6, Stress-strain responses from adjusted splitting tests.

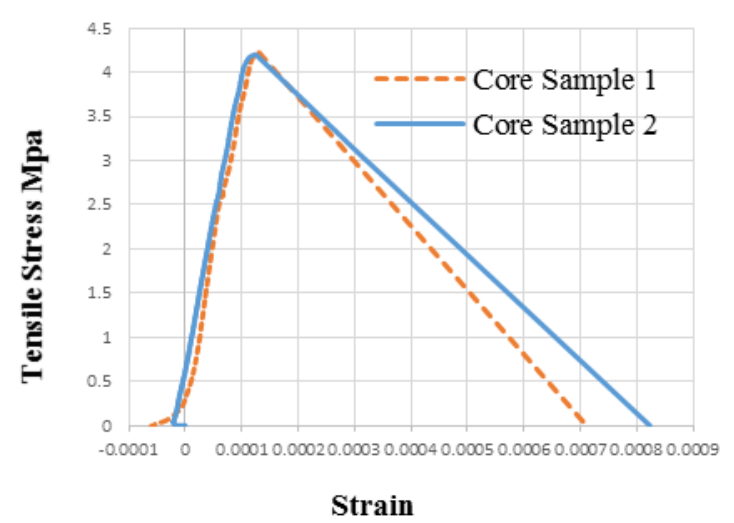

Figure 7, Stress-strain for both core samples.

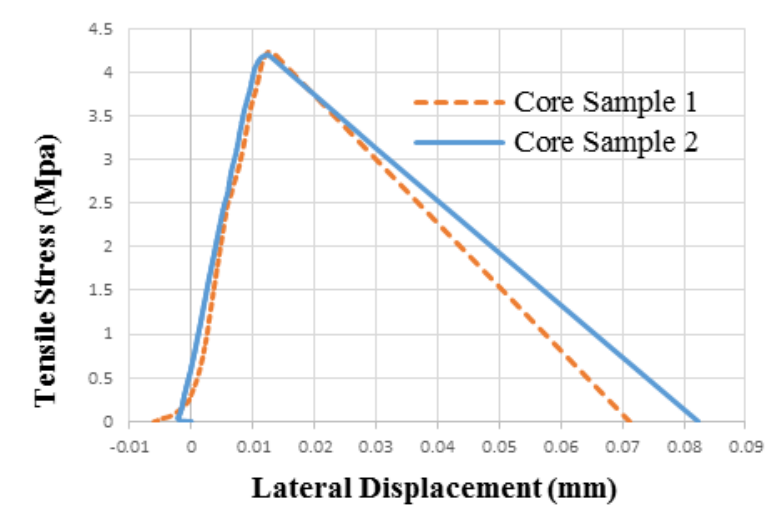

Figure 8, Stress-lateral displacement curve.

The experimental results in Figure 7 agree reasonably with a linear tension softening model of typical concrete in ABAQUS [11], which assumes that the tensile strain at the initial damage point is around 0.0001 and the tensile strain at a final failure point is approximately 10 times to its initial value, i.e. 0.001. As shown in Figure 7 the initial damage strain for both cores is close to 0.0001 and the average final strain extrapolated from core sample responses is around 7.5 times to its initial strain. Figure 8 
shows stress-lateral displacement curves of two samples. The corresponding fracture energy $G_{f}$ is equal to the area under the curves and can be determined using Equation 2 [9].

$G_{f}=\frac{1}{2}\left(f_{t} w_{c}\right)$

Where, $\mathrm{w}_{\mathrm{c}}$ is the characteristic lateral displacement when cracks occurred. The value of $\mathrm{w}_{\mathrm{c}}$ is calculated as 0.071 and 0.08 for sample 1 and sample 2 respectively. Thus, the averaged fracture energy for the samples is calculated as $0.15 \mathrm{~N} / \mathrm{mm}$ using Equation 2. Poisson's ratio of the core samples is not determined experimentally due to some technical difficulties in this investigation. Previous researchers estimated the Poisson's ratio as 0.17 based on the compressive strength of tested core samples between 64 and $125 \mathrm{MPa}$ [23]. Table 2 gives a summary of the ageing concrete properties.

Table 2: Ageing concrete material properties.

\begin{tabular}{|c|c|}
\hline Concrete property & Experimental result \\
\hline Compressive strength MPa & $67 \mathrm{MPa}$ \\
\hline Modulus of Elasticity MPa & $38728 \mathrm{MPa}$ \\
\hline Poisson's Ratio & 0.17 \\
\hline Tensile failure strength MPa & $4.2 \mathrm{MPa}$ \\
\hline Fracture energy & $0.15 \mathrm{~N} / \mathrm{mm}$ \\
\hline
\end{tabular}

\section{An ageing concrete material model}

The material properties of ageing concrete determined from the experimental work are used to create an ageing concrete material model (ACMM). The model is implemented into a UMAT subroutine in FEA commercial software ABAQUS to verify the splitting tests and further investigate the ageing concrete behaviour. This concrete constitutive model is created as a three-dimensional linear softening damage model for plain concrete. The constitutive model includes linear elastic, damage initiation and damage evolution to the failure. Before the damage initiation, material is in the elastic stage, i.e. the stress-strain curve is defined using elasticity matrix based on Hooke's law shown in Equation 3 [25]:

$$
\sigma=D^{e}: \varepsilon \text { when } \varepsilon<\varepsilon_{0}
$$

Where, $D^{e}$ is elastic stiffness matrix for plain concrete, $\varepsilon_{0}$ is tensile strain at initial damage, and $\sigma, \varepsilon$ are current stress and strain, respectively. Damage initiation refers to the onset of material degradation, it will initiate if material tensile strength or compressive strength is reached. The damage initiation point 
is addressed in the UMAT subroutine using material damage initiation conditions for tensile and compressive stress given in Equations 4 and 5.

$$
\begin{aligned}
& \varepsilon=\frac{\sigma_{t}^{0}}{D^{e}} \text { when } \varepsilon=\varepsilon_{t}^{0} \\
& \varepsilon=\frac{\sigma_{c}^{0}}{D^{e}} \text { when } \varepsilon=\varepsilon_{c}^{0}
\end{aligned}
$$

Where, $\sigma_{t}^{o}$ and $\varepsilon_{t}^{o}$ are tensile stress and strain respectively when damage initiates; $\sigma_{c}^{o}$ and $\varepsilon_{c}^{o}$ are compressive stress and strain respectively at initial damage stage. After damage initiation, the material strength and stiffness begin to degrade as damage evolves. Material damage evolution can be expressed by the rate of material stiffness degradation. The degraded stress $\sigma^{d}$ can be formulated using damaged matrix given by Equation 6 [25].

$$
\sigma^{d}=D^{d}: \varepsilon \text { when } \varepsilon_{0}<\varepsilon<\varepsilon_{f}
$$

Where, $D^{d}$ is the damaged elasticity matrix formulated mathematically based on scalar damage approach defined in Equation 7, which was proposed by previous researchers including [27-33] $D^{d}=(1-d) D^{e}$

Where, $d$ is the material damage scale to describe damage evolution from damage initiation to total failure. It should be noted that concrete material would no longer behave isotropic feature, thus an anisotropic damage matrix given in Equation 8 is proposed to be used in the damage evolution. This anisotropic damage matrix is used to define the linear softening behaviour which is the function of three damage scales $d x, d y$ and $d z$, in the directions $x, y$ and $z$ respectively. The anisotropic damage model including the effects of different degradation in different directions is more reliable for simulating concrete damage behaviour compared to the isotropic damage model [31]. From Equation 8, only the damages in principal directions are considered to describe the damage behaviour. Whereas, for the coupled behaviour, the corresponding mixed damage parameters contributed to measure the damage behaviour in the coupling items. 


$$
D^{d}=\frac{E}{(1-2 v)(1+v)}\left[\begin{array}{cccccc}
(1-v)\left(1-\mathrm{d}_{x}\right) & v\left(1-d_{x}\right)\left(1-\mathrm{d}_{y}\right) & v\left(1-d_{x}\right)\left(1-\mathrm{d}_{z}\right) & 0 & 0 & 0 \\
v\left(1-d_{x}\right)\left(1-\mathrm{d}_{y}\right) & (1-v)\left(1-\mathrm{d}_{y}\right) & v\left(1-d_{z}\right)\left(1-\mathrm{d}_{y}\right) & 0 & 0 & 0 \\
v\left(1-d_{x}\right)\left(1-\mathrm{d}_{z}\right) & v\left(1-d_{z}\right)\left(1-\mathrm{d}_{y}\right) & (1-v)\left(1-\mathrm{d}_{z}\right) & 0 & 0 & 0 \\
0 & 0 & 0 & \frac{1-2 v}{2}\left(1-\mathrm{d}_{x}\right)\left(1-\mathrm{d}_{y}\right) & 0 & 0 \\
0 & 0 & 0 & 0 & \frac{1-2 v}{2}\left(1-\mathrm{d}_{z}\right)\left(1-\mathrm{d}_{y}\right) & 0 \\
0 & 0 & 0 & 0 & 0 & \frac{1-2 v}{2}\left(1-\mathrm{d}_{x}\right)\left(1-\mathrm{d}_{z}\right)
\end{array}\right]
$$

Where, the damage scale $d_{i}(i=x, y, z)$ given in Equation 9 has been used by a number of previous researchers to account for reduction of stiffness in terms a bilinear softening damage law shown in Figure 9 [32-36, 44, 45].

$$
d_{i}=\frac{\varepsilon_{f i}\left(\varepsilon_{d i}-\varepsilon_{0 i}\right)}{\varepsilon_{d i}\left(\varepsilon_{f i}-\varepsilon_{0 i}\right)}, \quad i=x, y, z
$$

In Equation 9, $\varepsilon_{0 i}$ is initial damage strain, $\varepsilon_{d i}$ is current damage strain, $\varepsilon_{\mathrm{fi}}$ is the final damage strain at zero tensile stress. The value of damage scale ranges from zero to one. Zero damage scale indicates no damage initiated. When the damage scale equals to 1, a fracture is raised. Equations 8 and 9 are used to create the ACMM through UMAT in ABAQUS. The flow chart of the ACMM is illustrated in Figure 10.

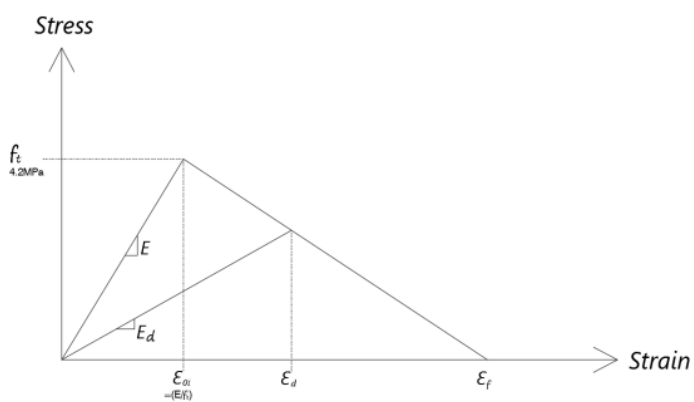

Figure 9, A bilinear softening damage law

The experimental properties given in Table 2 are used to determine the parameters required by Equations 8 and 9. The fracture energy obtained from Figure $7 \& 8$ (area under the curve) is used to describe the softening part of ACMM model and define the final damage strain shown in Figure 9. Tensile failure strength with modulus of elasticity is used to determine initial damage strain. 
The ACMM has two main functions: updating the stresses and the solution-dependent state variables, and updating the material Jacobian matrix [11]. The constitutive Jacobian is required to define in the UMAT coding for governing the convergence rate while solving nonlinear equation systems [11]. Jacobian matrix can be calculated using Equation 10 [37] to determine the changes in the $i_{\text {th }}$ stress component at the end of the time increment caused by an infinitesimal perturbation of the $j_{t h}$ component of the strain increment array.

$\frac{\partial \Delta \sigma}{\partial \Delta \varepsilon}=D^{d}+\frac{\partial D^{d}}{\partial \varepsilon} \varepsilon=D^{d}+\frac{\partial D^{d}}{\partial d_{x}} \frac{\partial d_{x}}{\partial \varepsilon}: \varepsilon+\frac{\partial D^{d}}{\partial d_{y}} \frac{\partial d_{y}}{\partial \varepsilon}: \varepsilon+\frac{\partial D^{d}}{\partial d_{z}} \frac{\partial d_{z}}{\partial \varepsilon}: \varepsilon$

Where, $\frac{\partial \Delta \sigma}{\partial \Delta \varepsilon}$ is stress increment caused by strain increment array; $\frac{\partial D^{d}}{\partial d_{x, y, z}}$ is derivative of the damaged matrix in respect to the damage scales; $\frac{\partial d_{x, y, z}}{\partial \varepsilon(I)}$ is derivative of the damage scales with respect to the strains, which can be further formulated to update Jacobian as given in Equation 11.

$$
\frac{\partial d_{x, y, z}}{\partial \varepsilon(I)}=\frac{\left[\varepsilon_{f} \varepsilon_{d(\mathrm{x}, \mathrm{y}, \mathrm{z})}\left(\varepsilon_{f}-\varepsilon_{t, c}\right)\right]-\left[\left(\varepsilon_{f}-\varepsilon_{t, c}\right)\left(\varepsilon_{d(\mathrm{x}, \mathrm{y}, \mathrm{z})}-\varepsilon_{t, c}\right) \varepsilon_{f}\right]}{\left[\varepsilon_{d(\mathrm{x}, \mathrm{y}, \mathrm{z})}\left(\varepsilon_{f}-\varepsilon_{t, c}\right)\right]}
$$

A nonlinear parameter of viscous regularization is incorporated in the UMAT to improve the numerical convergence rate. The viscous parameter is applied through Equation 12 [37].

$$
\left.d_{x, y, z}^{R}\right|_{t^{n+1}}=\left.\left[\mathrm{d}_{x, y, z}^{R} \frac{\eta}{\eta+\Delta t}\right]\right|_{t^{n}}+\left.d_{x, y, z} \frac{\Delta t}{\Delta t+\eta}\right|_{t^{(n+1)}}
$$

Where, $\eta$ is the viscosity parameter, $d_{x, y, z}^{R}$ is regularized damage scale, $t^{n+1}$ and $t^{n}$ means increment and last increment.

\section{Numerical verification of the ACMM using smeared concrete cracking model}

A standard smeared cracking model in ABAQUS is used to verify the ACMM. A plain concrete sample under tension and a McNeice reinforced concrete slab are simulated for this purpose. It should be noted that these two samples are fresh concrete with no ageing degradation. The concrete properties used in both smeared cracking model and the ACMM are given in Table 3. The nonlinear concrete properties 
used in modelling for uniaxial tension and compression are given in Table $4 \& 5$, the initial tension softening strain in Table 5 is 0.002 used for both smeared cracking model and the ACMM [40].

Table 3: Elastic properties of concrete and steel bars.

\begin{tabular}{|c|c|}
\hline Elastic properties & Values \\
\hline Elastic modulus of concrete, $E_{c}$ & $28600 \mathrm{MPa}$ \\
\hline Passion's Ratio of concrete, $v_{c}$ & 0.15 \\
\hline Elastic modulus of Rebar, $E_{s}$ & $200000 \mathrm{MPa}$ \\
\hline Yield stress of steel, $F_{y}$ & $345 \mathrm{MPa}$ \\
\hline Density of Concrete & $2400 \mathrm{~kg} / \mathrm{m}^{3}$ \\
\hline Density of Steel & $7800 \mathrm{~kg} / \mathrm{m}^{3}$ \\
\hline
\end{tabular}

Table 4: Compressive properties of plain concrete.

\begin{tabular}{|c|c|c|}
\hline Post-cracking stages & Stress MPa & Plastic Strain \\
\hline $\begin{array}{c}\text { Initial compressive yield } \\
\text { stress point }\end{array}$ & 20.68 & 0 \\
\hline Ultimate stress point & 37.92 & 0.0015 \\
\hline
\end{tabular}

Table 5: Tensile properties in smeared cracking model.

\begin{tabular}{|c|c|c|}
\hline Post-cracking stages & Stress MPa & Strain \\
\hline Initial damage point at Cracking & 3.17 & 0.00011 \\
\hline Final failure point at Collapse & 0 & $\begin{array}{c}0.00011+\text { initial tension } \\
\text { softening strain }\end{array}$ \\
\hline
\end{tabular}




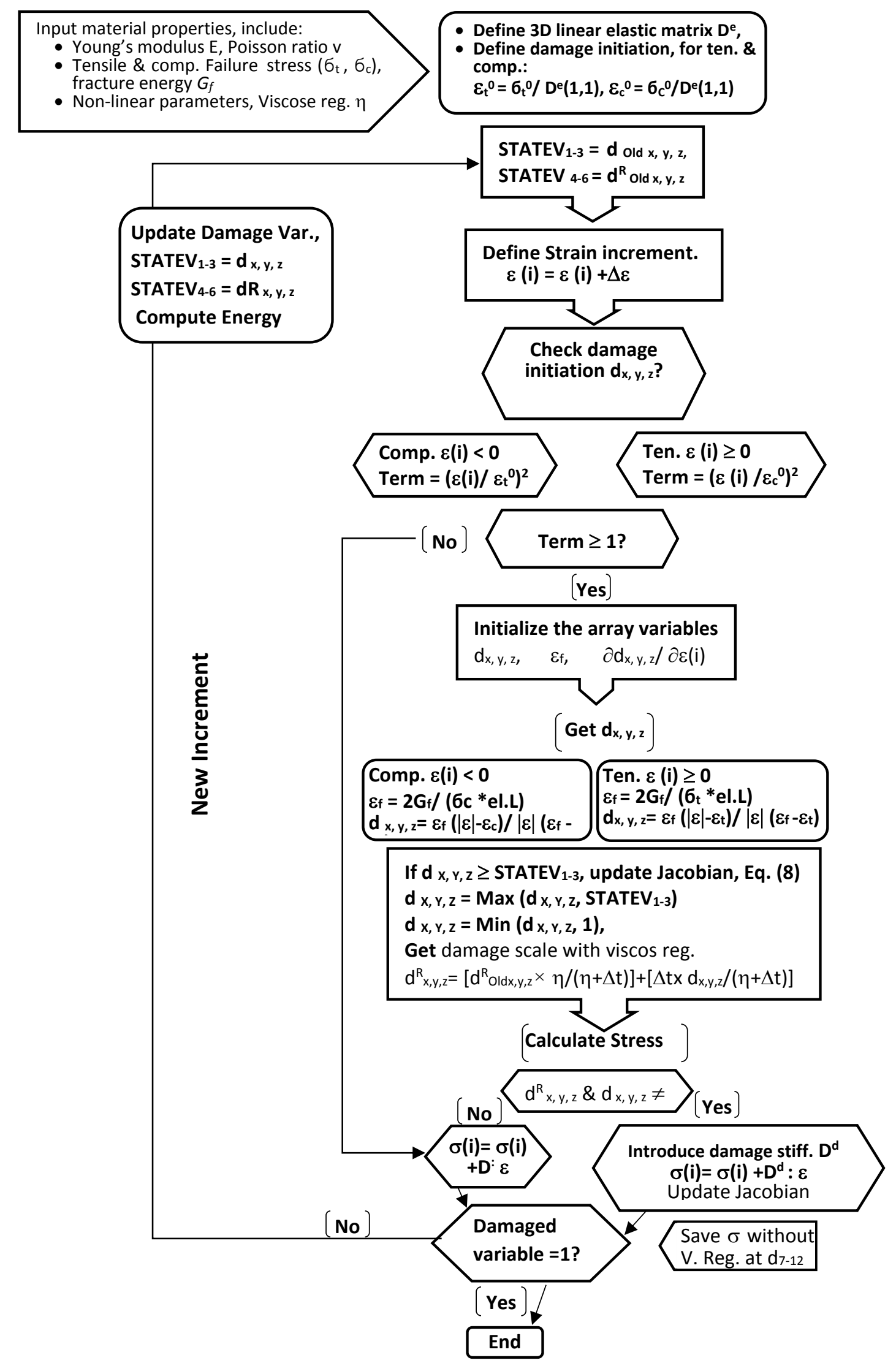

Figure 10, The flow chart of the ACMM 


\subsection{Concrete cube in tension}

A simple solid element of a plain concrete cube under tension is analysed using both the ACMM and smeared cracking model. Load-displacement responses generated by these two models are given in Figure 11. It can be seen from Figure 11 that both the ACMM and smeared model predict an almost same material failure response. This investigation indicates that the material is completely damaged in the pulling direction (X-axis), while damage scales in the other directions ( $\mathrm{Y} \& \mathrm{Z})$ are zero.

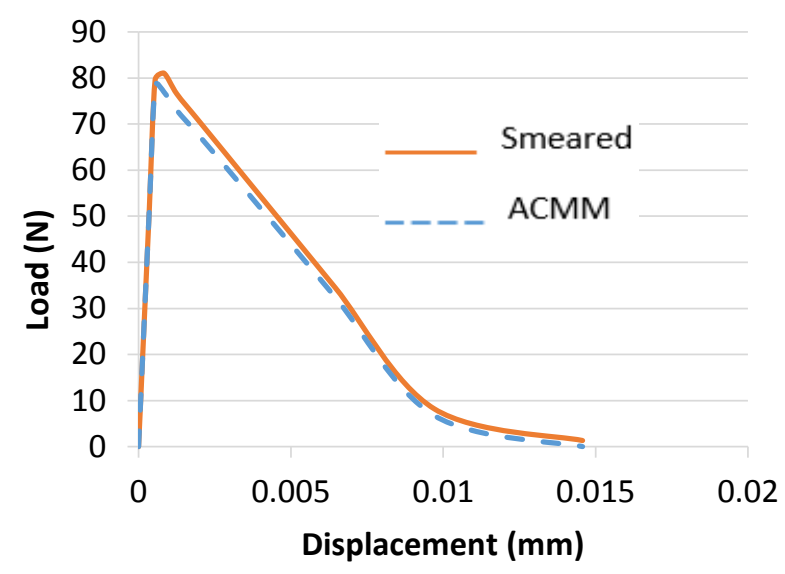

Figure 11, Load-displacement responses from both the ACMM and smeared crack model

\subsection{Reinforced concrete slab}

A reinforced concrete slab tested by McNeice (1967) has been analysed by number of researchers [3841]. The reinforced concrete McNeice slab has a square shape with $44.45 \mathrm{~mm}$ thickness and $914.4 \mathrm{~mm}$ side length. Owing to the symmetry conditions, only one-quarter of the reinforced concrete slab is simulated using solid elements for concrete, with line elements representing reinforced steel bars. The slab is supported at its four corners and loaded at the centre. The steel bars are introduced in both directions at $25 \%$ of the slab depth from tension side as shown in Figure 12. The ratio of volumes for steel bars to the concrete is 0.085 in both directions. The load-displacement responses from experimental test, the ACMM and FEA smeared cracking model are shown in Figure 13. It can be seen from Figure 13 that the load-deflection response obtained from ACMM shows a good agreement with the test results and smeared crack modelling. 

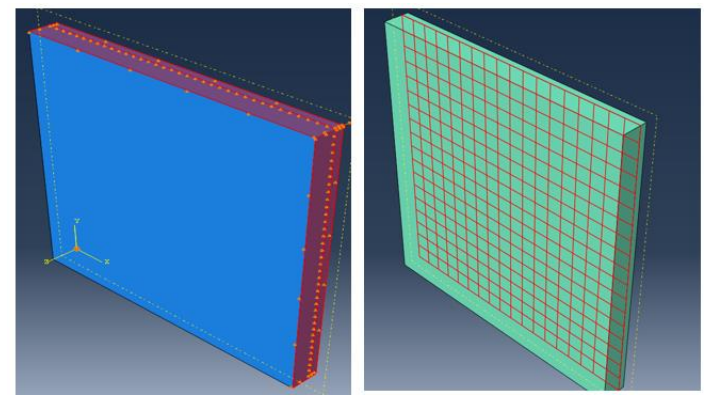

Figure 12, A quarter model of the concrete slab.

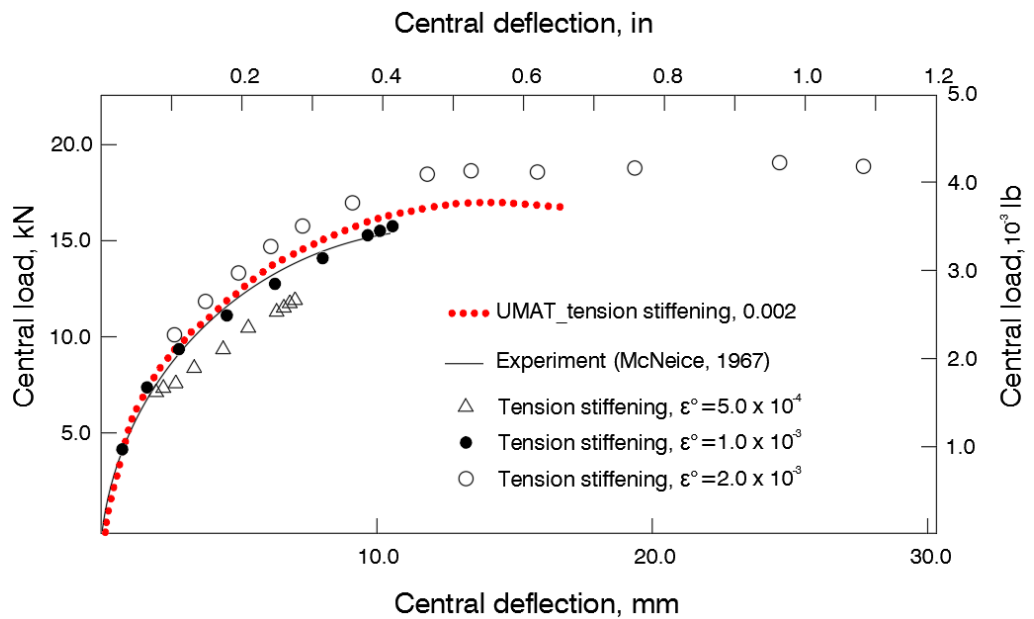

Figure 13, Load-deflection responses given by the ACMM, test and smeared crack model.

\section{Modelling of splitting tensile test}

The developed ACMM is used to simulate the splitting tensile test of the core samples, and the cohesive element in ABAQUS is used for comparison in this example. The test sample is ageing concrete since concrete properties determined from laboratory tests given in Table 2 are used for both the ACMM and cohesive element model. In the ACMM based approach, standard solid elements with a combination of C3D8 and C3D6 are used in simulation. A compressive load is applied along the length of the cylinder of the curved surface shown in Figure 14. The cylinder is supported vertically at the base opposite the loading line. Meanwhile, an ABAQUS based cohesive element model is used in this example for comparison [42]. A quarter of the sample is simulated as shown in Figure 15. Linear elastic properties are used to define concrete material through standard plane strain element CPE4R. The cohesive element (COH2D4) in ABAQUS is introduced at the splitting zone to define cracking behaviour of the 
failure plane. Figure 16 shows a cohesive element simulated splitting failure of ageing concrete sample, presented by the maximum principal strain contour. The failed cohesive elements start from the centre of the cylinder and moves up towards the loading position on the top surface. This is reflected by the strain variation from 0.05 at the centre to 0.01 at the top surface along the failed cohesive element zone shown in Figure 16.

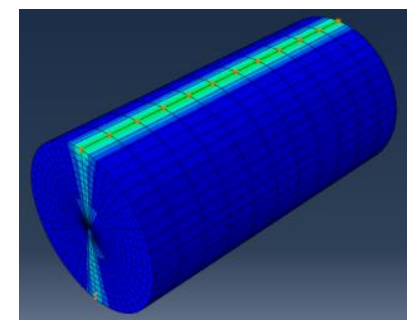

Figure 14, The ACMM simulated splitting failure of the ageing concrete

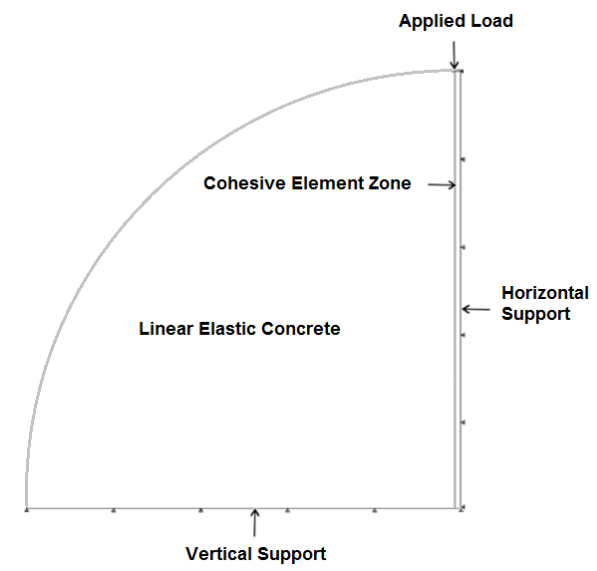

Figure 15, A quarter modelling of ageing concrete sample in splitting test
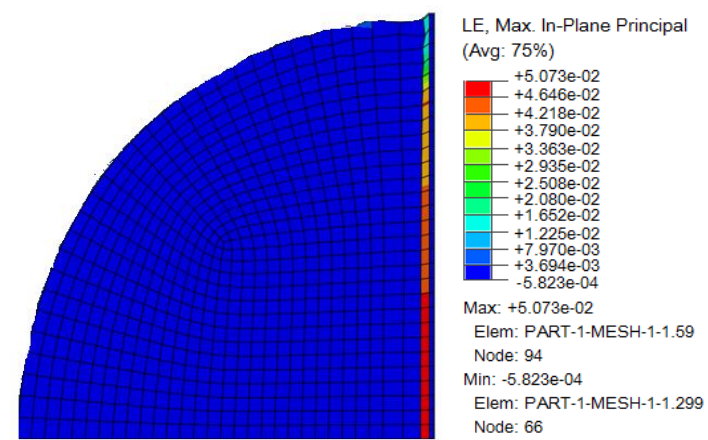

Figure 16, A cohesive element simulated splitting failure of the ageing concrete

Figure 17 shows the load-displacement curves given by the ACMM, cohesive element model and experimental work. It can be seen from Figure 17 that the initial readings attained for the experimental 
results can potentially be inaccurate. This is simply caused by the unstable positions in the testing machine. The load-displacement curve of the core sample 1 is almost linear response since $10 \mathrm{kN}$ load applied, with a slight direction change around $80 \mathrm{kN}$ possibly due to micro cracks occurred. When the ultimate load about $130 \mathrm{kN}$ is reached the load-displacement curve begins to drop down. The response of core sample 2 initially moves horizontally in the negative direction, then, followed by a good linear response in elastic stage up to the ultimate point where it begins to drop down. At the peak point, the predicted ultimate load is almost same with that from sample 1 . The maximum principal stress generated at the centre of the sample under the ultimate load has reached the tensile failure strength of concrete, therefore, cracks initiate and propagate. At post failure stage the core sample 1 is slightly softer than the core sample 2. In general, the load-displacement responses from experimental test, the ACMM and cohesive element modelling have a reasonable agreement at the elastic stage. The failure load given by the ACMM is slightly lower than the tested failure load about $130 \mathrm{kN}$ and cohesive element prediction by $5 \%$. The responses in post failure stage, the predictions from both the ACMM and cohesive element are not completed due to convergent problems in nonlinear analysis, however, they have a trend to test results.

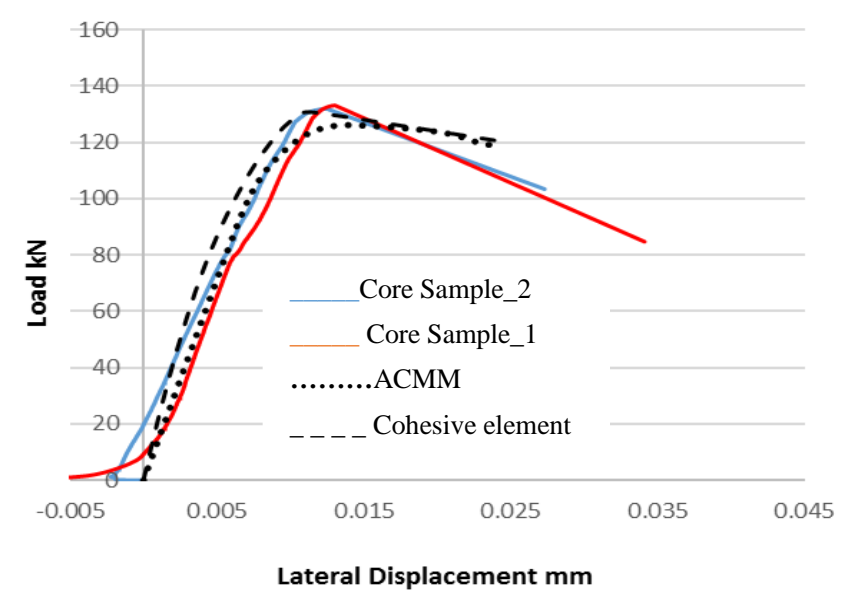

Figure 17, Load-lateral displacement curves from test, the ACMM and cohesive element

\section{Conclusion}

Basic mechanical properties of the ageing concrete are obtained using test methods specified in BS EN standards. Standard splitting test method specified in BS EN 12390-6 is adjusted with a lateral 
expansion measurement rig for generating tensile strength and fracture energy. A 3D ageing concrete material model (ACMM) is created in terms of tested data. This ACMM model is developed through the UMAT in ABAQUS, and validated by selected ageing concrete core samples and fresh concrete samples together with smeared crack modelling and cohesive element modelling.

The approach of investigating ageing concrete in this paper provides a general approach to study ageing material properties. The developed ACMM can be used for simulating the behaviour of ageing concrete structures in the future. Future work would also consider the effect of year-length scale on degradation of concrete material properties, thus an ageing concrete material model with scaling effect would be developed for residual life prediction of ageing concrete structures.

\section{Reference}

1. Lakshmikandhan, K. N, Sivakumar, P, Ravichandran, R., Damage Assessment and Strengthening of Reinforced Concrete Beams, International Journal of Material and Mechanical Engineering (IJMME), 2(2) (2013).

2. Bourahla, N., Attar, A., Tafraout, S., Djidjeli, F., \& Kenai, S, Effect of ageing degradation on the performance of reinforced concrete bridge piers under seismic excitations. ICCBT (2008), Seoul, Korea.

3. Timothy P. Dolen, P.E., Materials Properties Model of Aging Concrete. US Department of interior. Retrieved from: http://www.usbr.gov/ssle/damsafety/TechDev/DSOTechDev/DSO05-05.pdf (2005).

4. Zhu, X. Q., \& Law, S. S., A concrete-steel interface element for damage detection of reinforced concrete structures. Engineering Structures, 29(12) (2007), 3515-3524.

5. Sanayei, M., \& Onipede, O., Damage assessment of structures using static test data. AIAA journal, 29(7) (1991), 1174-1179.

6. Cerri, M. N., \& Vestroni, F., Detection of damage in beams subjected to diffused cracking. Journal of Sound and Vibration, 234(2) (2000), 259-276.

7. Allen, R.T.L., Concrete in coastal structures. London (1998): Thomas Telford.

8. Ghaemmaghami, A., \& Ghaemian, M., Specific fracture energy appromoxation of dam concrete (2004). IIT. Retrieved from: http://www.iitk.ac.in/nicee/wcee/article/13 69.pdf

9. Hillerborg, A., Modéer, M., \& Petersson, P. E., Analysis of crack formation and crack growth in concrete by means of fracture mechanics and finite elements. Cement and concrete research, 6(6) (1976), 773-781.

10. Petersson, P. E., Crack growth and development of fracture zones in plain concrete and similar materials (Doctoral dissertation, Division, Inst.) (1981). Retrieved from: http://www.iaea.org/inis/collection/NCLCollectionStore/_Public/13/668/13668228.pdf

11. ABAQUS, V. (2013). 6.13. Dassault systemes. Pawtucket.

12. British Standards Institute., BS EN 12390-3: Testing hardened concrete: Part 3: Compressive strength of test specimens (2009). Retrieved from https://bsol.bsigroup.com/Search/Search?searchKey $=B S+E N+12390 \&$ OriginPage $=H o m e+p$ age+search 
13. Vandegrift Jr, D., \& Schindler, A. K., The effect of test cylinder size on the compressive strength of sulphur capped concrete specimens. Highway Research Centre and Department of Civil Engineering at Auburn University, 83 (2006). http://www.eng.auburn.edu/files/file806.pdf

14. British Standards Institute., BS EN 12390-1: Testing hardened concrete: Part 1: Shape, dimensions and other requirements for specimens and moulds (2000). Retrieved from: https://bsol.bsigroup.com/Search/Search?searchKey $=B S+E N+12390 \& O$ riginPage $=$ Home $+p$ age+search

15. British Standards Institute, BS EN 12390-13: Testing hardened concrete: Part 13 Determination of secant modulus of elasticity in compression (2013). Retrieved from https://bsol.bsigroup.com/Search/Search?searchKey $=B S+E N+12390 \&$ OriginPage $=H o m e+p$ age+search

16. EMRCO, Guidance to the engineering properties of concrete (2006). Retrieved from http://www.ermco.eu/documents/ermcodocuments/guidance_to_the_engineering_properties_of_concrete_061129.pdf

17. British Standards Institute, BS EN 12390-6: Testing hardened concrete: Part 6: Tensile splitting strength of test specimens (2009). Retrieved from https://bsol.bsigroup.com/Search/Search?searchKey=BS+EN+12390\&OriginPage=Home+pa ge+search

18. Akita, H., Koide, H., \& Mihashi, H., Specimen geometry in uniaxial tension test of concrete. Proceedings FraMCoS-6. Taylor \& Francis, London (2007) 243-248.

19. Nanni, A., Splitting-tension test for fiber reinforced concrete. ACI Materials Journal, 85(4) (1988).

20. Graybeal, B. A., Material property characterization of ultra-high performance concrete (2006).

21. Lowes, L. N., Finite element modeling of reinforced concrete beam-column bridge connections (Doctoral dissertation, University of California, Berkeley) (1999). Retrieved from: http://faculty.washington.edu/lowes/dissertation/dissertation/dissertation.book\%28chapter2.P DF

22. Fib, Structural Concrete: Textbook on Behaviour, Design and Performance: Updated Knowledge of the CEB-FIP Model Code 1990 (No. 1-3). FIB-Féd. Int. du Béton. Retrieved from:

https://books.google.co.uk/books?id=Dl36ncDebRMC\&pg=PA33\&lpg=PA33\&dq=relation + compressive+to+tensile+strength + of + concrete $\&$ source $=$ bl\&ots $=\mathrm{mXkeOgYiGq} \&$ sig $=\mathrm{yDzj} 10 \mathrm{~K}$ Hn_Rp4GU5OPBDBI-M6a8\&hl=en\&sa=X\&ei=QrMRVcLjI-

uQ7Ab01YDQAQ\&ved=0CFIQ6AEwCQ\#v=onepage \&q=relation $\% 20$ compressive $\% 20$ to $\% 2$ 0tensile\%20strength\%20of\%20concrete \&f=true

23. Kumar, M., Ma, Z., \& Matovu, M., Mechanical Properties of High-Strength Concrete (2013). Retrieved from: http://www.acsu.buffalo.edu/ mkumar2/Wikiquake/Docs/ReportHSC.pdf

24. British Standards Institute, BS 1377-2: Soils for civil engineering purposes: Part2: Classification test (1990). Retrieved from: https://bsol.bsigroup.com/Search/Search?searchKey=BS1377\&OriginPage=Home+page+sear $\underline{\mathrm{ch}}$

25. Geers, M. G. D., Brekelmans, W. A. M., \& de Borst, R., Viscous Regularization of StrainLocalisation for Damaging Materials. In DIANA Computational Mechanics '94 (1994) 127-138, Springer Netherlands.

26. Hashin, Z., \& Rotem, A., A fatigue failure criterion for fiber reinforced materials. Journal of composite materials, 7(4) (1973) 448-464.

27. Hashin, Z., Failure criteria for unidirectional fiber composites. Journal of applied mechanics, 47(2) (1980) 329-334.

28. Camanho, P. P., \& Dávila, C. G., Mixed-mode decohesion finite elements for the simulation of delamination in composite materials (2002). Retrieved from: 
http://www.researchgate.net/profile/Carlos_Davila8/publication/24327361_Mixed-

Mode Decohesion Finite Elements for the Simulation of Delamination in Composite $M$ aterials/links/00b49527d4918f3b65000000.pdf

29. Matzenmiller, A. L. J. T. R., Lubliner, J., \& Taylor, R. L., A constitutive model for anisotropic damage in fiber-composites. Mechanics of materials, 20(2) (1995) 125-152.

30. Al-Rub, R. K. A., \& Kim, S. M., Computational applications of a coupled plasticity-damage constitutive model for simulating plain concrete fracture.Engineering Fracture Mechanics, 77(10) (2010) 1577-1603.

31. Chen, J., A numerical investigation of thermal-related matrix shrinkage crack and delamination in composite T-piece specimens using a modified interface cohesive model. Journal of Thermoplastic Composite Materials, 25(3) (2011) 267-282.

32. Chen, J., \& Fox, D., Numerical investigation into multi-delamination failure of composite Tpiece specimens under mixed mode loading using a modified cohesive model. Composite Structures, 94(6) (2012) 2010-2016.

33. Elmarakbi, A., Finite Element Analysis of Delamination Growth in Composite Materials using LS-DYNA: Formulation and Implementation of New Cohesive Elements. INTECH Open Access Publisher (2011). Retrieved from: http://cdn.intechopen.com/pdfs-wm/14307.pdf

34. Pinho, S. T., Iannucci, L., \& Robinson, P., Formulation and implementation of decohesion elements in an explicit finite element code.Composites Part A: Applied science and manufacturing, 37(5) (2006) 778-789.

35. Grassl, P., Xenos, D., Nyström, U., Rempling, R., \& Gylltoft, K. CDPM2: A damage-plasticity approach to modelling the failure of concrete. International Journal of Solids and Structures, 50(24) (2013) 3805-3816.

36. Qing, H., \& Mishnaevsky Jr, L., 3D constitutive model of anisotropic damage for unidirectional ply based on physical failure mechanisms. Computational Materials Science, 50(2) (2010) 479486.

37. Hand, F. R., Pecknold, D. A., \& Schnobrich, W. C., Nonlinear layered analysis of RC plates and shells. Journal of the structural division, 99(7) (1973) 1491-1505.

38. Lin, C. S., \& Scordelis, A. C., Nonlinear analysis of RC shells of general form. Journal of the Structural Division, 101(3) (1975) 523-538.

39. Gilbert, R. I., \& Warner, R. F., Tension stiffening in reinforced concrete slabs. Journal of the structural division, 104(12) (1978) 1885-1900.

40. Crisfield, M. A., Variable step-lengths for non-linear structural analysis (No. LR 1049 Monograph) (1982).

41. Denneman, E., Kearsley, E. P., \& Visser, A. T., Splitting tensile test for fibre reinforced concrete. Materials and structures, 44(8) (2011) 1441-1449.

42. J. Chen, Eric Ravey, Stephen Hallett and Michael Wisnom, Prediction of delamination in braided composite T-piece specimens, Composites Science and Technology, 69(2009) 2363 2367.

43. J. Chen, Simulation of multi-directional crack in braided composite T-piece specimens using cohesive models, Fatigue \& Fracture of Eng. Materials \& Structures, 34(2011) 123-130.

44. J. Chen, Predicting progressive delamination of stiffened fibre-composite panel and repaired sandwich panel by decohesion model, Thermoplastic Composite Materials, 15(5) (2002) 429 442. 